\title{
Palladium Nanocatalysts on Hydroxyapatite: Green Oxidation of Alcohols and Reduction of Nitroarenes in Water
}

\author{
Mohammadreza Shokouhimehr ${ }^{1, *(1)}$, Samaneh Mahmoudi-Gom Yek ${ }^{2}$, \\ Mahmoud Nasrollahzadeh ${ }^{3}$, Aejung Kim ${ }^{4}$ and Rajender S. Varma ${ }^{5, *} \mathbb{B}$ \\ 1 Department of Material Science and Engineering, Research Institute of Advanced Materials, Seoul National \\ University, Seoul 08826, Korea \\ 2 Department of Chemistry, Bu-Ali Sina University, Hamedan 65178, Iran; samamahmoudi@yahoo.com \\ 3 Department of Chemistry, Faculty of Science, University of Qom, Qom 3716146611, Iran; \\ mahmoudnasr81@gmail.com \\ 4 Asia Center, Seoul National University, Seoul 08826, Korea; ajk110@snu.ac.kr \\ 5 Regional Center of Advanced Technologies and Materials, Department of Physical Chemistry, Faculty of \\ Science, Palacky University, Šlechtitelů 27, 78371 Olomouc, Czech Republic \\ * Correspondence: mrsh2@snu.ac.kr (M.S.); varma.rajender@epa.gov (R.S.V.)
}

Received: 26 July 2019; Accepted: 30 September 2019; Published: 7 October 2019

\begin{abstract}
A green procedure is described for supporting Pd nanoparticles on hydroxyapatite (HAP), which serves as a highly-stable heterogeneous catalyst displaying excellent activity for the aqueous expeditious reduction of nitroaromatics to the corresponding amines with sodium borohydride, and oxidation of primary and secondary alcohols by hydrogen peroxide with high yields and selectivities. The structural features of the prepared catalyst are confirmed by latest techniques including field emission scanning electron microscopy, transmission electron microscopy, energy-dispersive X-ray spectroscopy, and X-ray photoelectron spectroscopy. The reusability of the heterogeneous catalyst was affirmed in the aqueous reduction of nitrobenzene and oxidation of cycloheptanol for six consecutive runs without significant loss of catalytic activity.
\end{abstract}

Keywords: hydroxyapatite; palladium nanocatalysts; heterogeneous catalysis; oxidation; reduction; alcohol; nitrobenzene

\section{Introduction}

Nanoparticle-based catalysts (nanocatalysts) are propounded as competent candidates for heterogeneous catalysis due to their enhanced catalytic activities and selectivities [1-4]; their surface area increases as the size decreases. As a result, a high catalytic activity and eventually a semi-homogeneous system can be attained [5-7]. In addition, the easy separation and reuse of the nanocatalysts is a very important feature of such catalytic systems, which ultimately results in the clean preparation of pure products [8-10], although most unsupported nanocatalysts have several drawbacks, namely their separation and reuse from the reaction mixture. The leftover nanocatalytic residues may have deleterious effects in the production of fine chemicals and pharmaceuticals [11-14]. Consequently, various supports have been examined for stabilizing such metal nanocatalysts in sustainable processes that facilitates separation, recovery, and reuse. A large number of solid supports have been studied including carbon nanotubes, alumina, zeolites mesoporous silica, metal-organic frameworks, organic polymers, and resins in the organic transformations [15-18]. Hydroxyapatite (HAP) is among the most applicable supports having many advantages such as (i) immobilization of well-defined monomeric active species on the surface because of their high adsorption capacity and ion exchangeability; (ii) its 
weak acid-base properties, preventing plausible side reactions caused by the supports; and (iii) the nonporous structure that facilitates overcoming problems that limit mass transfer $[19,20]$. Indeed, $\mathrm{HAP}$ is a support with several appropriate properties with the formula $\mathrm{Ca}_{10}\left(\mathrm{PO}_{4}\right)_{6}(\mathrm{OH})_{2}$; specific features being its capability to form solid solutions and possessing a wide range of cationic and anionic substituents that can help stabilize the anchored nanocatalysts. Consequently, it facilitates the separation process for the immobilized nanocatalysts, thus enhancing their reusability [21]; various noble metal nanocatalysts including $\mathrm{Au}, \mathrm{Pd}$, Pt, etc., have been immobilized on the surface of rigid HAP support, thus exploiting the heterogeneity advantages and easy recovery and recycling of the adorned nanocatalysts [22].

Many important chemical processes rely on the catalytic oxidation and reduction pathways in [23-26], and traditionally these reactions are conducted using expensive homogeneous catalysts and toxic organic solvents often under gas pressure (e.g., oxygen or hydrogen) [27-29]. Alcohols are used as precursors for several acids, aldehydes, and ketones, wherein the oxidation of alcohols is necessary for producing paints, plastics, detergents, food additives, cosmetics, and drug intermediates [30]. On the other side, the reduction of nitroarenes to their corresponding arylamines is among the major organic transformations because of their use as one of the important precursors and intermediates for the preparation of pharmaceuticals, dyes, pigments, polymers, and agrochemicals [31-33]. Pd nanoparticles (NPs) have a huge potential role in these processes [34-37]. In the present study, we synthesized Pd nanocatalysts supported on HAP (HAP-Pd) via a greener procedure using coffee extract in water. The activity of the HAP-Pd catalyst was verified in the reduction of nitroarenes in water and environmentally-friendly oxidation of alcohols. The obtained results showed that this supported $\mathrm{Pd}$ nanocatalyst is very effective as a heterogeneous catalyst.

\section{Experimental Section}

All chemicals were procured from Aldrich, Fluka, and Merck chemical companies and used without any further purification. Field emission scanning electron microscopy (FESEM) was recorded using a Sigma Carl Zeiss instrument. Transmission electron microscopy (TEM) images were acquired by JEM-2100 (JEOL Ltd., Tokyo, Japan). Furthermore, the HAP-Pd catalyst was analyzed by X-ray photoelectron spectroscopy (XPS) using an Al K $\alpha$ source (Sigma probe, VG Scientifics). High-resolution powder X-ray diffraction (HRXRD) was acquired using a Bruker D8 Advance instrument. Moreover, we performed energy-dispersive X-ray spectroscopy (EDX) by a TESCAN mira3 apparatus. The reactions were monitored using gas chromatography mass spectrometers (GC-MS) using an Agilent Technologies 7693 Autosampler and 5977A mass selective detector r GC-MS.

HAP-Pd catalyst was prepared by modifying previously documented methods [38]. In a typical synthesis, $1 \mathrm{~g}$ HAP was dispersed in $100 \mathrm{~mL}$ distilled water containing $500 \mathrm{mg}$ of coffee powder. $100 \mathrm{mg} \mathrm{K} \mathrm{K}_{2} \mathrm{PdCl}_{4}$ dissolved in water was added dropwise to the aforementioned solution under vigorous stirring. The mixture was stirred for $8 \mathrm{~h}$ at room temperature to produce HAP-supported Pd nanocatalysts. The product was washed with sufficient deionized water and filtered several times to remove any non- and/or poorly-anchored Pd NPs.

The hydrogenation of nitroarenes was performed using the HAP-Pd catalyst with aqueous $\mathrm{NaBH}_{4}$ as a reducing agent. In a typical procedure, the HAP-Pd catalyst $(1 \mathrm{~mol} \%)$ was dispersed in deionized $\mathrm{H}_{2} \mathrm{O}$. Then, a nitroaromatic, $\mathrm{NaBH}_{4}$, and a small stirring bar were added into the reaction glass flask and the reaction mixture was stirred at room temperature under air atmosphere.

The oxidation of alcohols was similarly accomplished in a small round-bottom flask with the HAP-Pd catalyst ( $1 \mathrm{~mol} \%$ ) dispersed in $\mathrm{H}_{2} \mathrm{O}$. Then, the starting alcohol, $\mathrm{H}_{2} \mathrm{O}_{2} 30 \%$, and a small stirring bar were placed in the flask and the reaction mixture was heated in an oil bath $\left(90^{\circ} \mathrm{C}\right)$ and with constant stirring under air and ambient atmosphere.

\section{Results and Discussion}

The morphology, shape, and size of the prepared catalyst were identified by Field emission scanning electron microscopy (FESEM) and TEM techniques. Transmission electron microscopy (TEM) 
images show the homogeneous distribution of spherical Pd NPs immobilized on the HAP with average diameters of $\sim 5 \mathrm{~nm}$ (Figure 1a-c). The scanning TEM (STEM) images clearly affirm that the Pd NPs were comprised of nano-sized particles with approximately spherical morphology (Figure 1d).

Comparison study of the energy-dispersive X-ray spectroscopy (EDX) images of HAP (Figure 2) and HAP-Pd (Figure 3) confirmed the successful preparation of the HAP-Pd, with the grain of the spherical Pd NPs pervading a good combination on the HAP surface. As shown in the EDX spectrum (Figure 3), the presence of Pd authenticated the FESEM analysis for the stabilization of Pd NPs on the HAP.

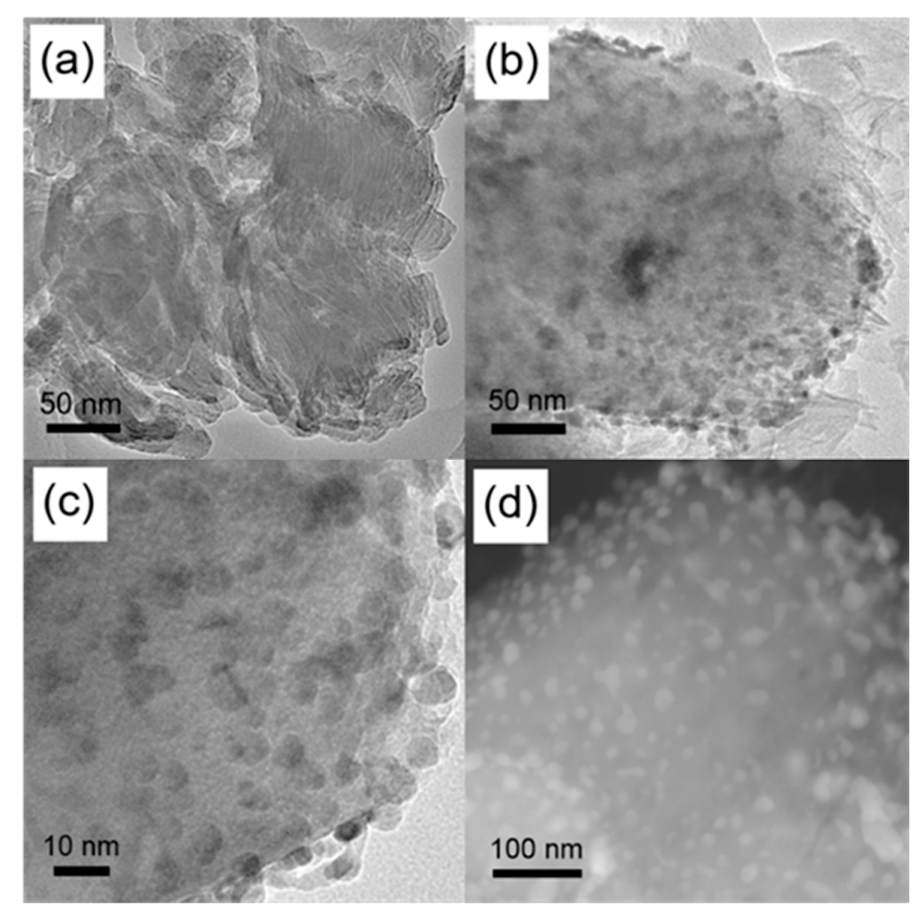

Figure 1. TEM images of (a) HAP, and (b) HAP-Pd catalyst. (c) HRTEM image of HAP-Pd catalyst. (d) STEM image of HAP-Pd catalyst.
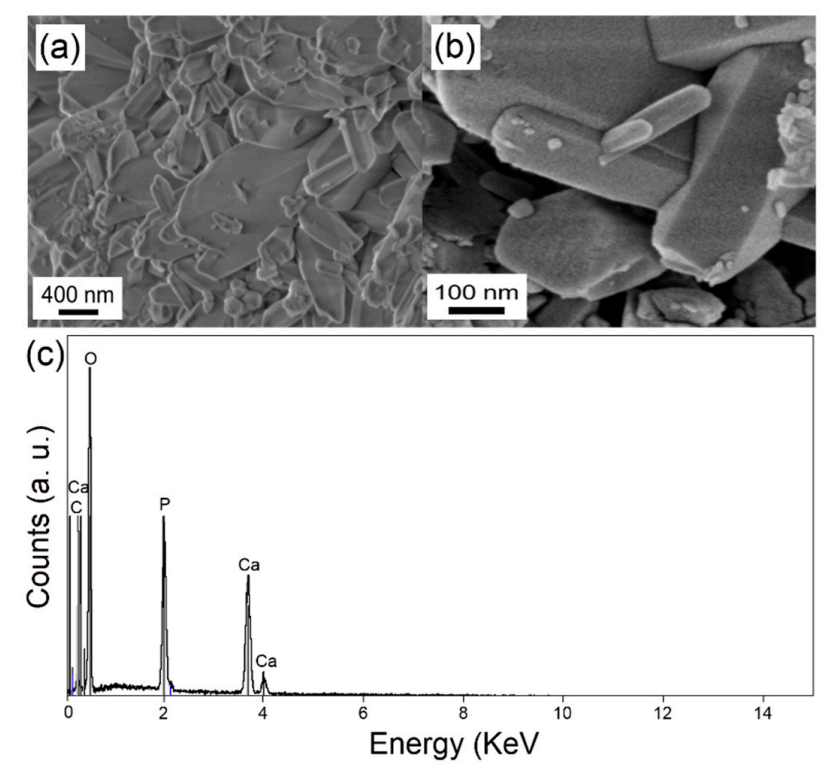

Figure 2. (a) Low, and (b) high magnification FESEM images of HAP. (c) EDX spectrum of HAP. 

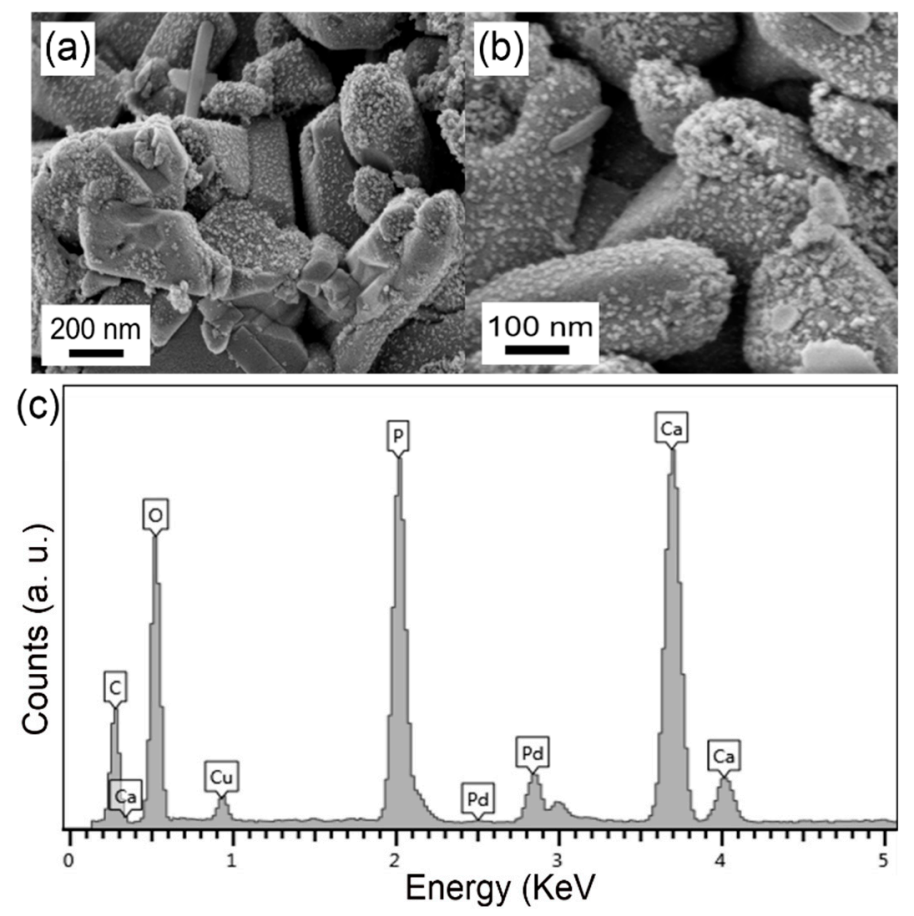

Figure 3. (a) Low, and (b) high magnification FESEM images of HAP-Pd catalyst. (c) EDX spectrum of HAP-Pd catalyst.

The EDX mapping of the HAP-Pd catalyst provides the qualitative results for the distribution of the existing elements in the prepared catalyst matrix; projected distributions of $\mathrm{P}, \mathrm{Ca}$, and $\mathrm{Pd}$ within the HAP-Pd catalyst are shown in Figure 4. The compositional map confirms the homogeneous distribution of all of the elements in the HAP-Pd catalyst and clearly ascertains the uniformity of the prepared catalyst. The surface composition of the HAP-Pd catalyst was also confirmed by XPS (Figure 5). The survey spectrum shows the surface binding situation, establishing the presence of $C$, $\mathrm{Ca}, \mathrm{O}, \mathrm{P}$, and Pd elements in the synthesized catalyst.
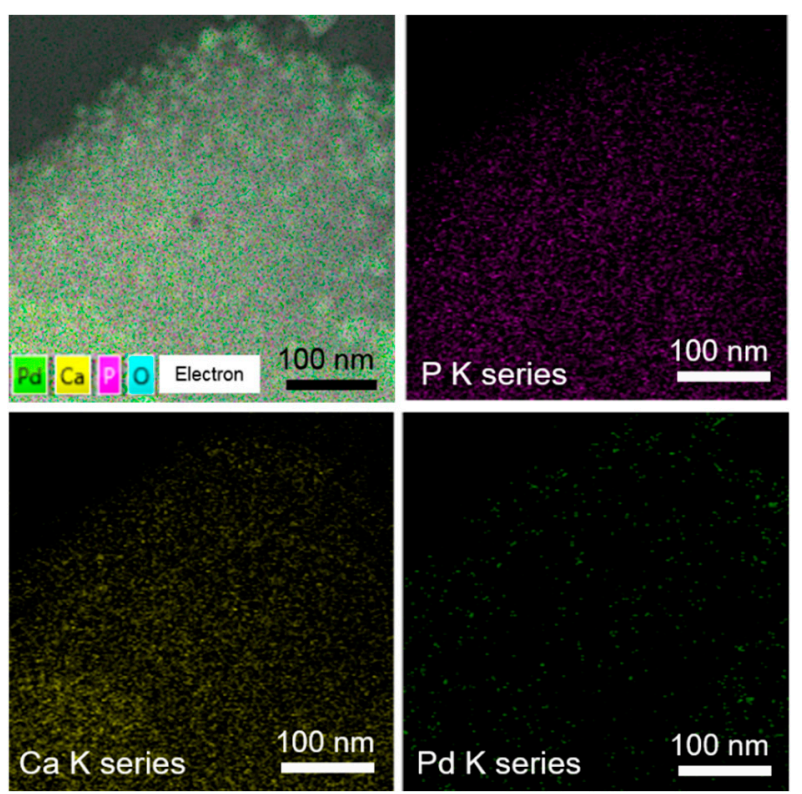

Figure 4. Elemental mapping of HAP-Pd catalyst confirming the presence of $\mathrm{P}, \mathrm{Ca}$, and $\mathrm{Pd}$ elements in the prepared catalyst. 


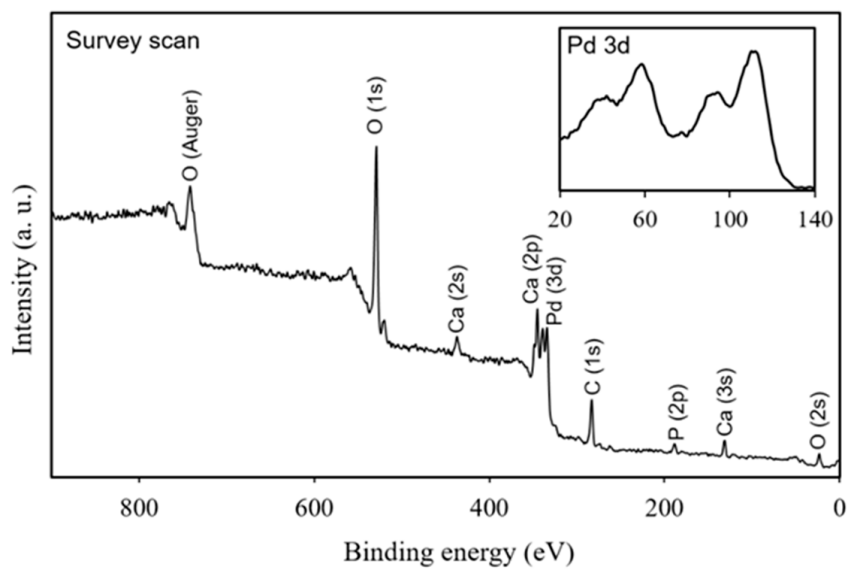

Figure 5. XPS analysis of the HAP-Pd catalyst. The inset shows Pd 3d scan.

The X-ray diffraction (HRXRD) pattern of the Pd-HAP catalyst is shown in Figure 6. The intense Bragg's peaks are observed at $2 \theta=25.88,28.97,31.77,32.2,32.9,34.05,35.4,39.2,39.8,42.03,43.08,46.7$, 48.1, 49.47, 64.08, 77.18, and 78.23 [39]. The positions and relative intensities of these peaks clearly match with literature data from the joint committee on powder diffraction system of HAP crystallite $\left(\mathrm{Ca}_{10}\left(\mathrm{PO}_{4}\right)_{6}(\mathrm{OH})_{2}\right.$, JCPDS 09-0432), indicating that the structure of the HAP support has not changed after supporting the Pd nanocatalysts. Five characteristic peaks of $\mathrm{Pd}$ appearing at $2 \theta=40.11,46.66$, 68.12, 82.1, and 86.62. (Pd, JCPDS 46-1043) were observed for the HAP-Pd catalyst.

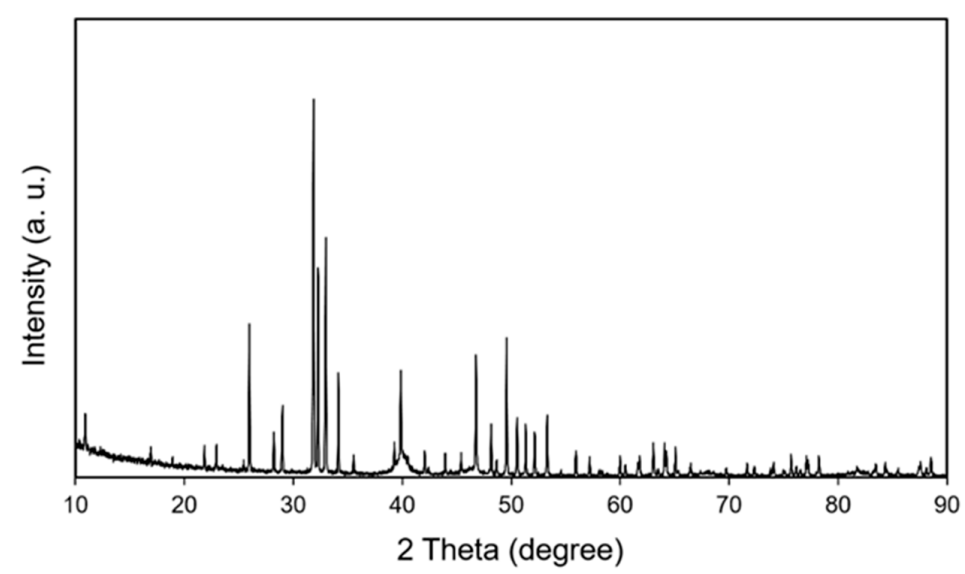

Figure 6. HRXRD pattern of HAP-Pd catalysts.

To better elucidate the effect of the mild reduction process on Pd NPs morphology and size on the HAP support in this study, we carried out control experiments using commonly-used reductant, $\mathrm{NaBH}_{4}$, by adapting previously reported procedures [40]. Although the Pd NPs were formed very rapidly on the HAP support, they instantly aggregated right after addition of $\mathrm{NaBH}_{4}$. TEM and HRTEM images show that the agglomeration of Pd NPs is unavoidable if they are immobilized using harsh reductant (Figure S1). We examined the possibility of immobilizing Pd NPs uniformly and discretely on another solid support, such as carbon, using the introduced mild procedure, and successfully loaded Pd NPs on carbon material. The TEM images of carbon before and after nanocatalyst loading show that the Pd NPs can be stabilized on carbon using this green protocol (Figure S2).

Today, growing attention is being paid to green chemistry in organic synthesis using environmentally-friendly processes. Many scientists have accentuated the significance of the greener methods to synthesize heterogeneous catalysts and chemicals [41]. Aqueous solvent provides an ideal alternative as an ecologically-safe media for particular use in this regard. In this investigation, after a greener synthesis of the HAP-Pd catalyst, we explored the catalytic activity of Pd nanocatalysts for the 
hydrogenation of nitro compounds in water. Based on the obtained results (Table 1), the reduction of nitroarenes possessing electron donating or withdrawing functions was fulfilled successfully in high yields. Although predicting the exact mechanism of the reactions is rather challenging, we propose the following mechanistic pathway for the formation of aminoaromatics from nitroarenes in this work (Scheme 1). As shown in Scheme 1, the reduction of nitroarenes was carried out using $\mathrm{NaBH}_{4}$ as the reducing agent, which entails two stages in the hydrogenation of nitroarenes to aminoaromatics: (i) Absorption of nitroarene and hydrogen to the metal surfaces, and (ii) electron transfer assisted by metal surfaces from $\mathrm{BH}_{4}{ }^{-}$to nitroarene and then desorption of the amino compound.

Table 1. Heterogeneous reduction of substituted nitroaromatics catalyzed by the HAP-Pd catalyst ${ }^{\mathrm{a}}$.

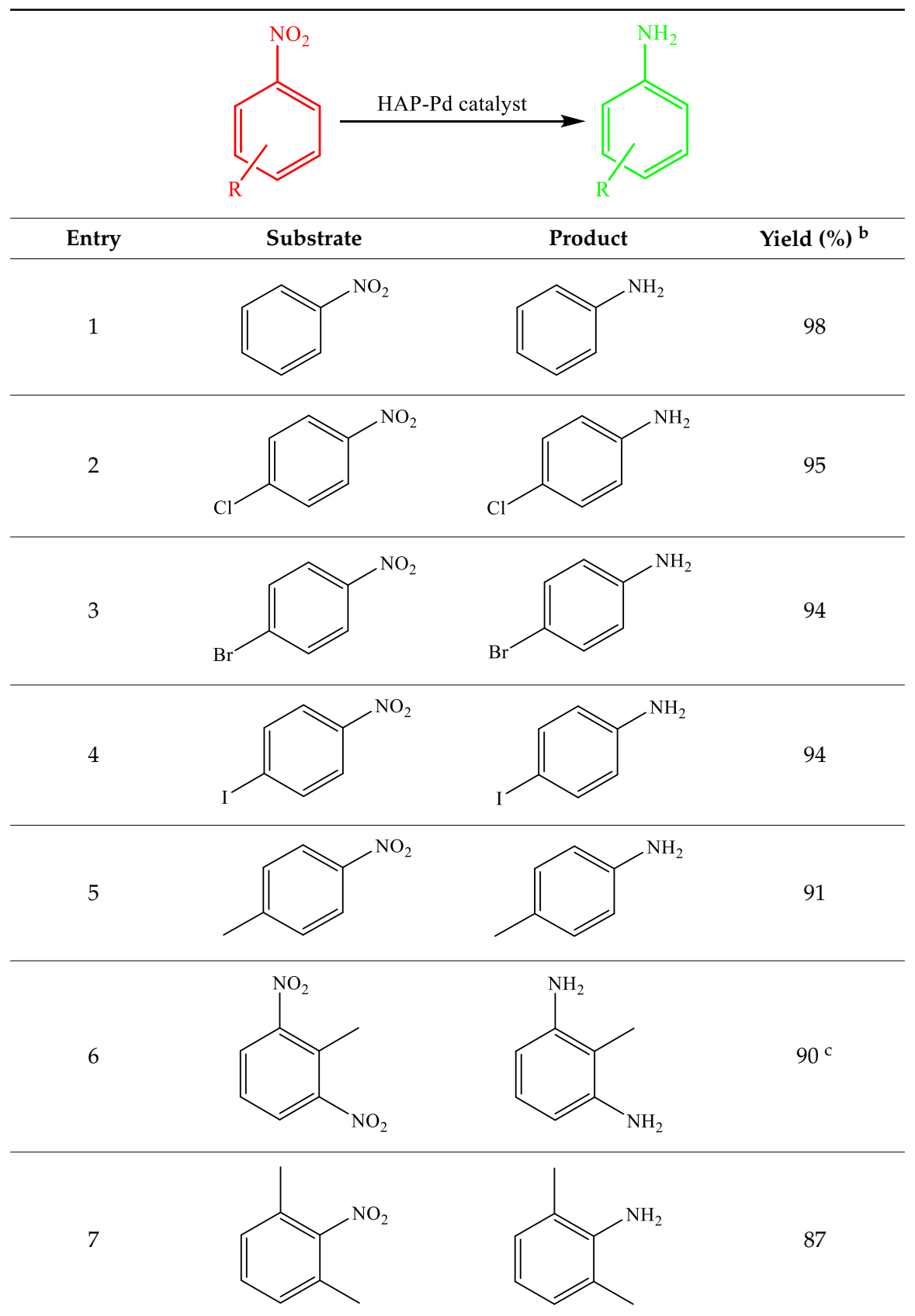

a Substituted nitroaromatics ( $1 \mathrm{mmol}), \mathrm{NaBH}_{4}$ (1.2 equiv.), HAP-Pd catalyst $(1 \mathrm{~mol} \%), \mathrm{H}_{2} \mathrm{O}(30 \mathrm{~mL})$, r.t., 2 h. ${ }^{\mathrm{b}}$ The yields were determined by GC-MS. ${ }^{c} 2.5$ equiv. $\mathrm{NaBH}_{4}$ was used. 


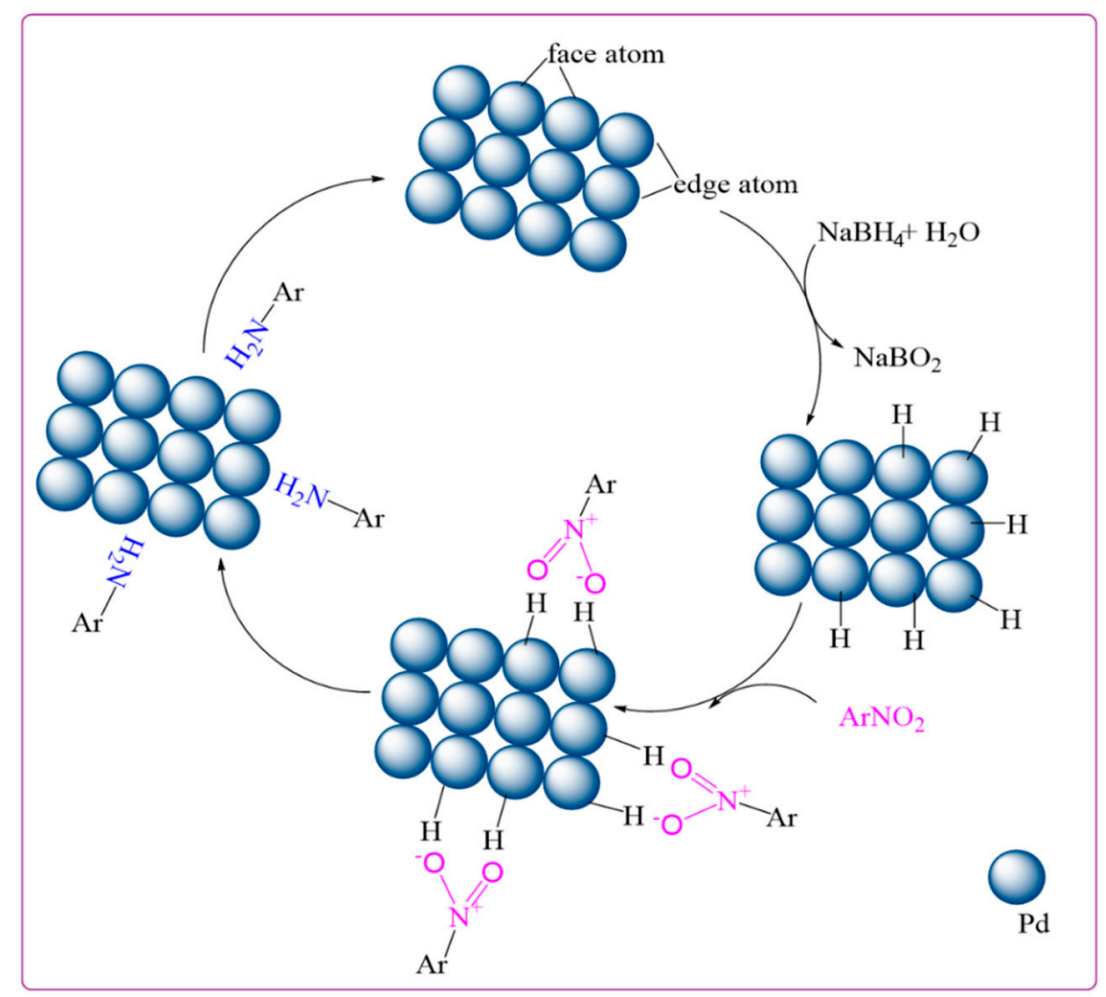

Scheme 1. A plausible mechanism for the reduction of nitroarenes catalyzed by the HAP-Pd catalyst.

Then, we compared the synthesis procedure and the catalytic activity of the HAP-Pd catalyst with the previously published catalysts in the reduction of nitrobenzene (Table S1). A facile synthetic method introduced in this study provided competitive catalytic conversion in mild reaction conditions, as compared to the complicated prepared catalysts [42,43]. To verify the advantages of the heterogeneous catalytic system, we carried out the reduction of nitrobenzene under homogeneous catalytic conditions using the water-soluble $\mathrm{K}_{2} \mathrm{PdCl}_{4}$ catalyst, which did not show reasonable catalytic activity under the reduction conditions (entry 1, Table S1). When $\mathrm{NaBH}_{4}$ was added to the reaction mixture, $\mathrm{K}_{2} \mathrm{PdCl}_{4}$ immediately aggregated forming large-sized particles. The reduction in the absence of the catalyst using $\mathrm{NaBH}_{4}$ also did not yield the expected product (entry 2, Table S1). Consequently, the friendly reaction medium containing HAP-Pd is an efficient catalytic tool for several important industrial organic transformations with numerous advantages such as benign catalytic system, high yield of products, and the deployment of nontoxic solvent. In addition, the utilization of water soluble reductant and oxidant (e.g., $\mathrm{NaBH}_{4}$ and $\mathrm{H}_{2} \mathrm{O}_{2}$ ) in the absence of gas pressure provides less expensive, safer, and more environmentally-benign protocols.

Although dehydrogenation of primary and secondary alcohols using solid-supported Pd NPs, including HAP, has been profoundly investigated, they are generally attained under oxygen pressure using hazardous and toxic organic solvents [44]. Therefore, developing mild oxidation processes using $\mathrm{H}_{2} \mathrm{O}_{2}$ in a greener oxidant is decidedly important for heterogeneous Pd catalysts [45]. To expand the greener potential application of the synthesized HAP-Pd catalyst, we examined the oxidation of primary and secondary alcohols in water using $\mathrm{H}_{2} \mathrm{O}_{2}$ as an oxidant; Table 2 summarizes the results of the dehydrogenative oxidation of benzyl alcohols catalyzed by HAP-Pd. Several primary and secondary alcohols were oxidized affording the desired products in good to excellent yields in water. It should be noted that the alcohol oxidation could not be achieved when we examined the oxidation of cycloheptanol under the identical reaction conditions but in the absence of the HAP-Pd catalyst; this catalytic system shows a marked ability to operate for a wide range of substrates under such optimized conditions. The precise mechanism for the heterogeneous oxidation of alcohols has not been delineated yet, but we proposed the following simplified pathway for the oxidation of alcohols 
using the HAP-Pd catalyst and $\mathrm{H}_{2} \mathrm{O}_{2}$ in this work (Scheme 2); the presence of Pd NPs plays a rather important role for the addition of hydrogen to alcohol by facilitating water elimination, and cleavage of $\mathrm{C}-\mathrm{H}$ and $\mathrm{O}-\mathrm{H}$ bonds of the alcohol to form an aldehyde or a ketone.

Table 2. Heterogeneous oxidation of alcohols catalyzed by the HAP-Pd catalyst ${ }^{\mathrm{a}}$.

Entry (\%) ${ }^{\mathbf{b}}$

a Reaction conditions: Alcohol (0.25 mmol), HAP-Pd catalyst $(1 \mathrm{~mol} \%), 90^{\circ} \mathrm{C}, \mathrm{H}_{2} \mathrm{O}_{2} 30 \%(5 \mathrm{mmol}), \mathrm{H}_{2} \mathrm{O}(3 \mathrm{~mL})$, $24 \mathrm{~h} .{ }^{\mathrm{b}}$ The yields were determined by GC-MS.
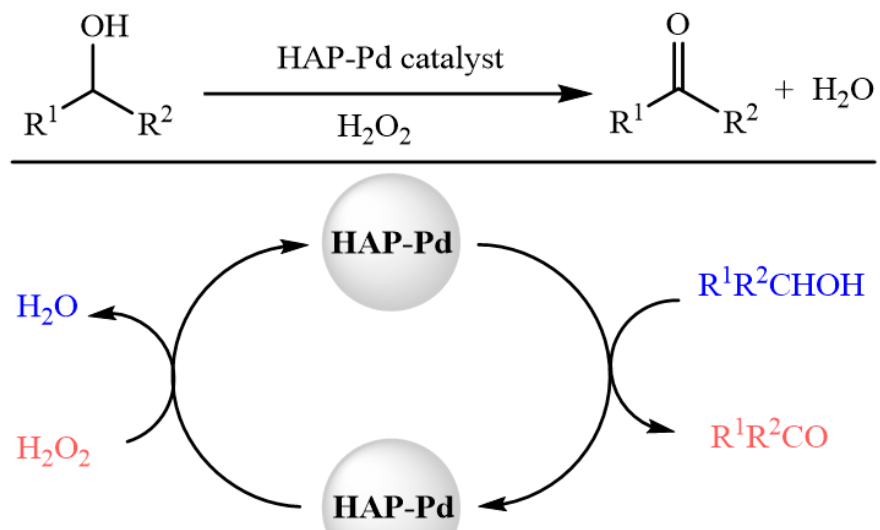

Scheme 2. A plausible pathway for the oxidation of alcohols catalyzed by the HAP-Pd catalyst. 
Furthermore, we studied the recyclability of the HAP-Pd catalyst in the reduction of nitrobenzene and oxidation of cycloheptanol as model reactions; Figure 7 illustrates the yield of the products with the number of cycles for the examined reactions. When the reaction was completed, the catalyst was separated from the reaction mixture, washed with deionized water, and dried in an oven for the subsequent runs. According to Figure 7, the catalyst could be recycled and reused for at least six runs with a negligible activity loss. The small reduction in the catalytic activity might be owing to the normal loss of the catalyst within the workup step.

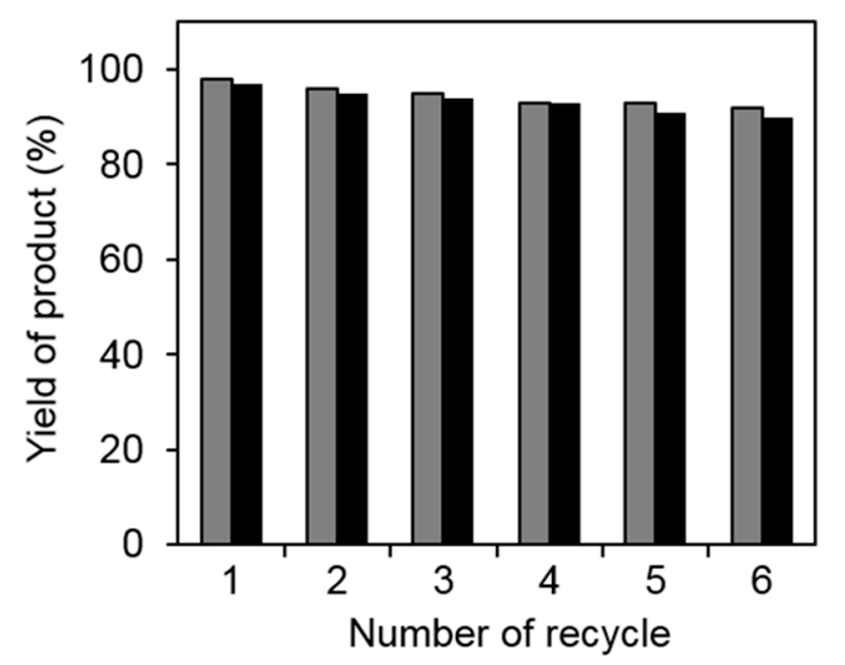

Figure 7. Reusability of HAP-Pd catalyst in heterogeneous reduction of nitrobenzene (gray columns) and oxidation of cycloheptanol (black columns).

\section{Conclusions}

In summary, we have successfully synthesized an efficient heterogeneous catalyst comprising hydroxyapatite-supported Pd nanoparticles (HAP-Pd). The prepared HAP-Pd catalyst was characterized using various techniques such as field emission scanning electron microscopy, transmission electron microscopy, energy-dispersive X-ray spectroscopy, and X-ray photoelectron spectroscopy. The designed catalyst displayed high catalytic efficiency for the reduction of nitroarenes to the corresponding amines with aqueous $\mathrm{NaBH}_{4}$, and similarly the oxidation of alcohols using $\mathrm{H}_{2} \mathrm{O}_{2}$ in water with high yield and selectivity. Additionally, the catalyst could be reused multiple times for the aforementioned reactions without significant loss of activity. Remarkably, several significant advantages were offered by the HAP-Pd catalyst in these greener transformations, which deliver high product yields in benign solvent-water.

Supplementary Materials: The following are available online at http://www.mdpi.com/2076-3417/9/19/4183/s1, Figure S1: TEM (a) and (b) HRTEM images of HAP-Pd catalyst synthesized by green coffee utilization. TEM (c) and (d) HRTEM images of Pd NPs decorated on HAP synthesized by NaBH4 utilization, Figure S2: TEM image of (a) carbon and (b) carbon-Pd catalyst synthesized by green coffee utilization, Figure S3: FT-IR spectra of (a) aniline, (b) 4-chloro aniline, (c) 4-bromo aniline, (d) 2,4-dimethyl aniline, (e) 4-methyl aniline. Table S1: A comparison study of catalytic activity with previously reported nanocatalysts.

Author Contributions: M.S. and R.S.V.; conceptualization. M.S., S.M.-G.Y., M.N. investigation; S.M.-G.Y., M.N. and A.K. formal analysis. All authors contributed to writing of original draft. M.S. and R.S.V. writing-review and editing.

Funding: This research received no external funding.

Conflicts of Interest: The authors declare no conflict of interest. 


\section{References}

1. Varma, R.S. Solvent-free organic syntheses using supported reagents and microwave irradiation. Green Chem. 1999, 1, 43-55. [CrossRef]

2. Varma, R.S. Sustainability via nanocatalysis. Curr. Opin. Green Sustain. Chem. 2019, 15, A1. [CrossRef]

3. Polshettiwar, V.; Varma, R.S. Green chemistry by nano-catalysis. Green Chem. 2010, 12, 743-754. [CrossRef]

4. Shokouhimehr, M. Magnetically separable and sustainable nanostructured catalysts for heterogeneous reduction of nitroaromatics. Catalysts 2015, 5, 534-560. [CrossRef]

5. Shylesh, S.; Schunemann, V.; Thiel,W.R. Magnetically separable nanocatalysts: Bridges between homogeneous and heterogeneous catalysis. Angew. Chem. Int. Ed. 2010, 49, 3428-3459. [CrossRef] [PubMed]

6. Shokouhimehr, M.; Hong, K.; Lee, T.H.; Moon, C.W.; Hong, S.P.; Zhang, K.; Suh, J.M.; Choi, K.S.; Varma, R.S.; Jang, H.W. Magnetically retrievable nanocomposite adorned with Pd nanocatalysts: Efficient reduction of nitroaromatics in aqueous media. Green Chem. 2018, 20, 3809-3817. [CrossRef]

7. Varma, R.S. Greener and sustainable trends in synthesis of organics and nanomaterials. ACS Sustain. Chem. Eng. 2016, 4, 5866-5878. [CrossRef]

8. Nasrollahzadeh, M.; Sajjadi, M.; Tahsili, M.; Shokouhimehr, M.; Varma, R.S. Synthesis of 1-substituted 1H-1,2,3,4-tetrazoles using biosynthesized Ag/sodium borosilicate nanocomposite. ACS Omega 2019, 4, 8985-9000. [CrossRef]

9. Kim, A.; Rafiaei, S.M.; Abolhosseini, A.; Shokouhimehr, M. Palladium nanocatalysts confined in mesoporous silica for heterogeneous reduction of nitroaromatics. Energy Environ. Focus 2015, 4, 18-23. [CrossRef]

10. Laali, K.K.; Shokouhimehr, M. The Pschorr reaction, a fresh look at a classical transformation. Curr. Org. Synth. 2009, 6, 193-202. [CrossRef]

11. Choi, K.H.; Shokouhimehr, M.; Sung, Y.E. Heterogeneous Suzuki cross-coupling reaction catalyzed by magnetically recyclable nanocatalysts. Bull. Korean Chem. Soc. 2013, 34, 1477-1480. [CrossRef]

12. Rafiaei, S.M.; Kim, A.; Shokouhimehr, M. Gadolinium triflate immobilized on magnetic nanocomposites as recyclable Lewis acid catalyst for acetylation of phenols. Nanosci. Nanotechnol. Lett. 2014, 6, 309-313. [CrossRef]

13. Choi, K.H.; Shokouhimehr, M.; Kang, Y.S.; Chung, D.Y.; Chung, Y.H.; Ahn, M.; Sung, Y.E. Preparation and characterization of palladium nanoparticles supported on nickel hexacyanoferrate for fuel cell application. Bull. Korean Chem. Soc. 2013, 34, 1195-1198. [CrossRef]

14. Shokouhimehr, M.; Shahedi Asl, M.; Mazinani, B. Modulated large-pore mesoporous silica as an efficient base catalyst for the Henry reaction. Res. Chem. Intermed. 2018, 44, 1617-1626. [CrossRef]

15. Maleki, M.; Beitollahi, A.; Shokouhimehr, M. Three-dimensionally interconnected porous boron nitride foam derived from polymeric foams. RSC Adv. 2016, 6, 51426-51434. [CrossRef]

16. Zhang, K.; Suh, J.M.; Choi, J.W.; Jang, H.W.; Shokouhimehr, M.; Varma, R.S. Recent advances in the nanocatalysts-assisted $\mathrm{NaBH}_{4}$ reduction of nitroaromatics in water. ACS Omega 2019, 4, 483-495. [CrossRef] [PubMed]

17. Zhang, K.; Hong, K.; Suh, J.M.; Lee, T.H.; Kwon, O.; Shokouhimehr, M.; Jang, H.W. Facile synthesis of monodispersed Pd nanocatalysts decorated on graphene oxide for reduction of nitroaromatics in aqueous solution. Res. Chem. Intermed. 2019, 45, 599-611. [CrossRef]

18. Alamgholiloo, H.; Zhang, S.; Ahadi, A.; Rostamnia, S.; Banaei, R.; Li, Z.; Liu, X.; Shokouhimehr, M. Synthesis of Bimetallic 4-PySI-Pd@Cu(BDC) via open metal site Cu-MOF: Effect of metal and support of Pd@Cu-MOFs in $\mathrm{H}_{2}$ generation from formic Acid. Mol. Catal. 2019, 467, 30-37. [CrossRef]

19. Fihri, S.A.; Len, C.; Varma, R.S.; Solhy, A. Hydroxyapatite: A review of syntheses, structure and applications in heterogeneous catalysis. Coord. Chem. Rev. 2017, 347, 48-76. [CrossRef]

20. Amer, W.; Abdelouahdi, K.; Ramananarivo, H.R.; Zahouily, M.; Fihri, A.; Djessas, K.; Zahouily, K.; Varma, R.S.; Solhy, A. Microwave-assisted synthesis of mesoporous nano-hydroxyapatite using surfactant templates. CrystEngComm 2014, 16, 543-549. [CrossRef]

21. Amer, W.; Abdelouahdi, K.; Ramananarivo, H.; Zahouily, M.; Fihri, A.; Coppel, Y.; Varma, R.S.; Solhy, A. Synthesis of mesoporous nano-hydroxyapatite by using zwitterions surfactant. Mater. Lett. 2013, 107, 189-193. [CrossRef] 
22. Gawande, M.B.; Bonifacio, V.D.B.; Luque, R.; Branco, P.S.; Varma, R.S. Benign by design: Catalyst-free in-water, on-water green chemical methodologies in organic synthesis. Chem. Soc. Rev. 2013, 42, 5522-5551. [CrossRef] [PubMed]

23. Moon, C.W.; Park, J.; Hong, S.P.; Sohn, W.; Andoshe, D.M.; Shokouhimehr, M.; Jang, H.W. Decoration of metal oxide surface with $\{111\}$ form Au nanoparticles using PEGylation. RSC Adv. 2018, 8, 18442-18450. [CrossRef]

24. Ahadi, A.; Rostamnia, S.; Panahi, P.; Wilson, L.D.; Kong, Q.; An, Z.; Shokouhimehr, M. Palladium comprising dicationic bipyridinium supported periodic mesoporous organosilica (PMO): Pd@Bipy-PMO as an efficient hybrid catalyst for Suzuki-Miyaura cross-coupling reaction in water. Catalysts 2019, 9, 140. [CrossRef]

25. Kwon, K.C.; Suh, J.M.; Varma, R.S.; Shokouhimehr, M.; Jang, H.W. Electrocatalytic water splitting and $\mathrm{CO}_{2}$ reduction: Sustainable solutions via single-atom catalysts supported on 2D materials. Small Methods 2019, 3. [CrossRef]

26. Haghighatzadeha, A.; Mazinani, B.; Shokouhimehr, M.; Samiee, L. Preparation of mesoporous $\mathrm{TiO}_{2}-\mathrm{SiO}_{2}$ by ultrasonic impregnation method and effect of its calcination temperature on photocatalytic activity. Desalin. Water Treat. 2017, 92, 145-151. [CrossRef]

27. Tafesh, A.M.; Weiguny, J. A review of the selective catalytic reduction of aromatic nitro compounds into aromatic amines, isocyanates, carbamates, and ureas using CO. Chem. Rev. 1996, 96, 2035-2052. [CrossRef] [PubMed]

28. Shokouhimehr, M.; Piao, Y.; Kim, J.; Jang, Y.; Hyeon, T. A magnetically recyclable nanocomposite catalyst for olefin epoxidation. Angew. Chem. Int. Ed. 2007, 46, 7039-7043. [CrossRef]

29. Shokouhimehr, M.; Kim, T.; Jun, S.W.; Shin, K.; Jang, Y.; Kim, B.H.; Kim, J.; Hyeon, T. Magnetically separable carbon nanocomposite catalysts for efficient nitroarene reduction and Suzuki reactions. Appl. Catal. A Gen. 2014, 476, 133-139. [CrossRef]

30. Mallat, T.; Baiker, A. Oxidation of alcohols with molecular oxygen on solid catalysts. Chem. Rev. 2004, 104, 3037-3058. [CrossRef] [PubMed]

31. Nasrollahzadeh, M.; Sajjadi, M.; Shokouhimehr, M.; Varma, R.S. Recent developments in palladium (nano)catalysts supported on polymers for selective and sustainable oxidation processes. Coord. Chem. Rev. 2019, 397, 54-75. [CrossRef]

32. Shokouhimehr, M.; Lee, J.E.; Han, S.I.; Hyeon, T. Magnetically recyclable hollow nanocomposite catalysts for heterogeneous reduction of nitroarenes and Suzuki reactions. Chem. Commun. 2013, 49, 4779-4781. [CrossRef] [PubMed]

33. Zhang, K.; Suh, J.M.; Lee, T.H.; Cha, J.H.; Choi, J.W.; Jang, H.W.; Varma, R.S.; Shokouhimehr, M. Copper oxide-graphene oxide nanocomposite: Efficient catalyst for hydrogenation of nitroaromatics in water. Nano Converg. 2019, 6, 6. [CrossRef] [PubMed]

34. Lee, I.; Joo, J.B.; Shokouhimehr, M. Graphene derivatives supported nanocatalysts for oxygen reduction reaction. Chin. J. Catal. 2015, 36, 1799-1810. [CrossRef]

35. Shokouhimehr, M.; Kim, J.H.; Lee, Y.S. Heterogeneous Heck reaction catalyzed by recyclable polymer-supported N-heterocyclic carbene-palladium complex. Synlett 2006, 4, 618-620. [CrossRef]

36. Uozumi, Y.; Nakao, R. Catalytic oxidation of alcohols in water under atmospheric oxygen by use of an amphiphilic resin-dispersion of a nanopalladium catalyst. Angew. Chem. Int. Ed. 2003, 42, 194-197. [CrossRef] [PubMed]

37. Mori, K.; Hara, T.; Mizugaki, T.; Ebitani, K.; Kaneda, K. Hydroxyapatite-supported palladium nanoclusters: A highly active heterogeneous catalyst for selective oxidation of alcohols by use of molecular oxygen. J. Am. Chem. Soc. 2004, 126, 10657-10666. [CrossRef] [PubMed]

38. Nadagouda, M.N.; Varma, R.S. Green synthesis of silver and palladium nanoparticles at room temperature using coffee and tea extract. Green Chem. 2008, 10, 859-862. [CrossRef]

39. Kamieniak, J.; Bernalte, E.; Foster, C.W.; Doyle, A.M.; Kelly, P.J.; Banks, C.E. High yield synthesis of hydroxyapatite (HAP) and palladium doped HAP via a wet chemical synthetic route. Catalysts 2016, 6, 119. [CrossRef]

40. Deraedt, C.; Salmon, L.; Gatard, S.; Ciganda, R.; Hernandez, R.; Ruiz, J.; Astruc, D. Sodium borohydride stabilizes very active gold. Chem. Commun. 2014, 50, 14194-14196. [CrossRef]

41. Osako, T.; Torii, K.; Uozumi, Y. Aerobic flow oxidation of alcohols in water catalyzed by platinum nanoparticles dispersed in an amphiphilic polymer. RSC Adv. 2015, 5, 2647-2654. [CrossRef] 
42. Verma, S.; Nasir Baig, R.B.; Nadagouda, M.N.; Varma, R.S. Selective oxidation of alcohols using photoactive VO@g-C ${ }_{3} \mathrm{~N}_{4}$. ACS Sustain. Chem. Eng. 2016, 4, 1094-1098. [CrossRef]

43. Jachuck, R.J.J.; Selvaraj, D.K.; Varma, R.S. Process intensification: Oxidation of benzyl alcohol using a continuous isothermal reactor under microwave irradiation. Green Chem. 2006, 8, 29-33. [CrossRef]

44. Shokouhimehr, M.; Shin, K.Y.; Lee, J.S.; Hackett, M.J.; Jun, S.W.; Oh, M.H.; Jang, J.; Hyeon, T. Magnetically recyclable core-shell nanocatalysts for efficient heterogeneous oxidation of alcohols. J. Mater. Chem. A 2014, 2, 7593-7599. [CrossRef]

45. Sharma, R.K.; Yadav, M.; Monga, Y.; Gaur, R.; Adholeya, A.; Zboril, R.; Varma, R.S.; Gawande, M.B. Silica-based magnetic manganese nanocatalyst-Applications in the oxidation of organic halides and alcohols. ACS Sustain. Chem. Eng. 2016, 4, 1123-1130. [CrossRef]

(C) 2019 by the authors. Licensee MDPI, Basel, Switzerland. This article is an open access article distributed under the terms and conditions of the Creative Commons Attribution (CC BY) license (http://creativecommons.org/licenses/by/4.0/). 